\title{
Application of PROSPECT for estimating Total Petroleum Hydrocarbons in contaminated soils from leaf optical properties
}

Guillaume Lassalle ${ }^{\mathrm{a}, \mathrm{b}}$, Sophie Fabre ${ }^{\mathrm{a}}$, Anthony Credoz ${ }^{\mathrm{b}}$, Rémy Hédacq ${ }^{\mathrm{b}}$, Georges Bertonic, Dominique Dubucq ${ }^{\mathrm{d}}$, Arnaud Elger

AUTHOR ADDRESS

${ }^{a}$ Office National d'Études et de Recherches Aérospatiales (ONERA), Toulouse, France

${ }^{\mathrm{b}}$ TOTAL S.A., Pôle d'Études et de Recherches de Lacq, Lacq, France

${ }^{\mathrm{c}}$ DYNAFOR, Université de Toulouse, INRA, Castanet-Tolosan, France

${ }^{\mathrm{d}}$ TOTAL S.A., Centre Scientifique et Technique Jean-Féger, Pau, France

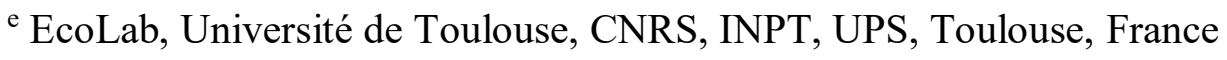

*Corresponding author: Guillaume Lassalle, Office National d'Études et de Recherches

Aérospatiales, 2 Avenue Edouard Belin, 31055 Toulouse, France; E-mail:

guillaume.lassalle@onera.fr; Tel.: +33562252931

Keywords: soil contamination, leaf optical properties, PROSPECT, pigment, total petroleum hydrocarbons 


\section{ABSTRACT}

Recent advances in hyperspectral spectroscopy suggest making use of leaf optical properties for monitoring soil contamination in oil production regions by detecting pigment alterations induced by Total Petroleum Hydrocarbons (TPH). However, this provides no quantitative information about the level of contamination. To achieve this, we propose an approach based on the inversion of the PROSPECT model. 1620 leaves from five species were collected on a site contaminated by 16 to 77 g. $\mathrm{kg}^{-1}$ of TPH over a 14-month period. Their spectral signature was measured and used in PROSPECT model inversions to retrieve leaf biochemistry. The model performed well for simulating the spectral signatures (RMSE $<2 \%$ ) and for estimating leaf pigment contents (RMSE $\leq 2.95 \mu \mathrm{g} \cdot \mathrm{cm}^{-2}$ for chlorophylls). Four out of the five species exhibited alterations in pigment contents when exposed to TPH. A strong correlation was established between leaf chlorophyll content and soil TPH concentrations $\left(\mathrm{R}^{2} \geq 0.74\right)$ for three of them, allowing accurate predictions of TPH $\left(\mathrm{RMSE}=3.20 \mathrm{~g} \cdot \mathrm{kg}^{-1}\right.$ and RPD $\left.=5.17\right)$. The accuracy of predictions varied by season and improved after the growing period. This study demonstrates the capacity of PROSPECT to estimate oil contamination and opens up promising perspectives for larger-scale applications. 


\section{Introduction}

In the last decades, increasing efforts have been made to improve the monitoring of past and current industrial activities [1-3]. The assessment of health and environmental risks remains a major issue as it requires efficient detection of contamination deriving from production facility failures and bad practices [4-6]. For this purpose, new approaches using hyperspectral spectroscopy have recently emerged in the oil and gas industry [7-8]. In exploiting the light absorption features of oil, these approaches have proved efficient for detecting and quantifying Total Petroleum Hydrocarbons (TPH) from the spectral signature of soils [9-10]. However, their applicability remains limited in vegetated areas, since only few radiations get through the foliage. As an alternative, recent studies have proposed exploiting the spectral signature of vegetation to detect reflectance changes induced by the presence of oil in soils [11-14].

The biophysical and biochemical parameters driving leaf optical properties are likely to be affected when vegetation is exposed to TPH [15-17]. This includes alterations in leaf anatomy (e.g. cuticle and parenchyma thickness), pigment and water contents [15-16, 18]. These effects mainly result from the modification of soil properties and the reduction of root uptake capacities [19-21]. They vary according to the species, the level of contamination and the duration of exposure. Alterations in leaf biophysical and biochemical parameters lead to reflectance changes, which help discriminate between healthy and affected vegetation $[12,22]$. Previous work focused on pigment alteration, since it is responsible for the increase in reflectance typically observed in the visible (VIS) when plants are exposed to TPH [23-25]. The amplitude of this increase is influenced by the level of contamination $[14,26]$. This suggests that leaf pigments could be used for detecting and quantifying oil contamination in vegetated areas. However, no method has been yet proposed in 
literature. Previous studies focused on quantifying heavy metal contamination deriving from mining or agricultural activities, a very different case of soil contamination [27-28].

Leaf pigments undergo significant changes throughout the year, depending on the season [2931]. Seasonal variations in pigment contents are therefore likely to hide the alterations induced by TPH. This can cause confusion and currently represents a major limitation for TPH detection under natural conditions. All the more so that not all species are good indicators of TPH, and their sensitivity to these contaminants is likely to affect the relative influence of TPH and seasons on leaf pigments and reflectance [12, 32-33].

The species established around industrial facilities are particularly tolerant to high levels of TPH [23, 34]. This makes it difficult to detect and estimate TPH, as this implies being able to differentiate small alterations in pigment contents using leaf optical properties. Many approaches have been developed in hyperspectral spectroscopy for estimating leaf pigment contents [35-38]. The physically-based model PROSPECT [39] proved to be one of the most reliable approaches across a wide range of ecological contexts [40-41]. The model has been recently improved and now enables pigment separation [42-43]. This is of major importance for detecting and estimating $\mathrm{TPH}$, since not all pigments are affected in the same way by contamination [24-25]. PROSPECT could therefore be used for detecting and estimating TPH-induced changes in leaf pigment contents and consequently for determining the level of soil contamination [23, 34].

This study proposes to assess the potential of leaf optical properties for predicting TPH concentrations in the soil, under natural temperate conditions. The proposed method is based on the retrieval of leaf pigment contents using the PROSPECT model, which are thereafter linked to TPH concentrations. The study was carried out on a range of plant species over a complete seasonal 
cycle in order to identify the most suitable conditions for predicting TPH. The proposed method was compared to other approaches typically used in similar studies.

2. Materials and Methods

2.1. Study site and species

The study was carried out on an industrial brownfield located in a temperate region. The site was subject to intensive oil and gas activities for 20 years, and production residues contaminated by TPH and heavy metals (HM) accumulated in the soil. Since then, it has been colonized by vegetation. The study focused on the predominant species, Rubus fruticosus L., which is generally well-established on industrial sites in temperate regions. Moreover, this species has already proved great potential in hyperspectral spectroscopy for detecting oil-induced pigment alterations $[12,25$, 32]. Other species found on the brownfield, including Quercus pubescens Wild., Populus $x$ canadensis Moench., Cornus sanguinea L. and Buddleja davidii Franch., were also tested for their sensitivity to TPH. The same species were also studied on an uncontaminated site (hereafter described as "control site") for comparison purposes. This site was located a few kilometers away from the brownfield and exhibited similar soil properties.

\subsection{Field sampling and measurements}

A mesh of 23 vegetated plots was defined, covering most of the brownfield. Plots consisted in areas of one meter in diameter and were spaced by 10 meters. The upper soil layer $(0-20 \mathrm{~cm})$ was analyzed for contaminants at the center of each plot. Analyses revealed $\mathrm{C}_{10}-\mathrm{C}_{40} \mathrm{TPH}$ concentrations ranging from 16 to $77 \mathrm{~g} \cdot \mathrm{kg}^{-1}$, the main contributors being in of the $\mathrm{C}_{21}-\mathrm{C}_{40}$ fraction (dense hydrocarbons). These concentrations correspond to a moderate to high level of exposure 
for plants, in comparison with other studies [16, 26]. High concentrations of HM and Polycyclic Aromatic Hydrocarbons (PAH) were also found. The detailed soil analyses are given in the Supporting Information.

Leaf samples were collected on site. For each species found in each plot, three young leaves were randomly sampled on different individuals. Their reflectance was measured in the [400:2500] nm domain using an ASD FieldSpec 4 Hi-Res spectroradiometer (Malvern Panalytical, Malvern, UK) and a leaf-clip with an internal light source. These measurements avoid the influence of leaf orientation and density and the effects of soil and atmosphere. Leaf radiance was acquired on a small black background panel and converted to reflectance as described in [25]. Measurements were carried out from June 2017 to October 2018, on a seasonal basis (Tab. 1). This included six different sampling dates, with samples taken in contrasted environmental conditions and at different phenological stages. On the same dates, additional spectral signatures were acquired on the control site. There were no TPH detected in the control soil and low HM concentrations corresponded to the geochemical background. Only B. davidii and R. fruticosus were found on the brownfield in March 2018. A total of 1620 spectral signatures had been collected on the brownfield by the end of the study. 152 leaves were used for determining water $\left(\mathrm{C}_{\mathrm{w}}\right)$, dry matter $\left(\mathrm{C}_{\mathrm{m}}\right)$ and pigment contents, following the procedures described in [44-45]. Pigments were analyzed by High Pressure Liquid Chromatography (HPLC). The chlorophyll content $\left(\mathrm{C}_{\mathrm{ab}}\right)$ was expressed as the sum of chlorophylls a and $\mathrm{b}$, and the carotenoid content $\left(\mathrm{C}_{\mathrm{xc}}\right)$ as the sum of $\beta$-carotene and xanthophylls. These analyses are detailed in the Supporting Information. They served to validate PROSPECT inversion outputs, as described in section 2.3. 
Table 1. Description of the sampling campaigns carried out on the brownfield. Only R. fruticosus and C. sanguinea were found on all 23 plots, except in March 2018.

\begin{tabular}{rccc}
\multicolumn{1}{c}{ Date } & $\begin{array}{c}\text { Species } \\
\text { found (n) }\end{array}$ & $\begin{array}{c}\text { Spectral } \\
\text { signatures (n) }\end{array}$ & Season \\
\hline June 2017 & 5 & 309 & Summer (heat waves) \\
October 2017 & 5 & 309 & Autumn \\
March 2018 & 2 & 75 & Late winter \\
April 2018 & 5 & 309 & Spring \\
June 2018 & 5 & 309 & Summer \\
October 2018 & 5 & 309 & Autumn
\end{tabular}

\subsection{PROSPECT inversion and validation}

The PROSPECT model was developed for simulating the hemispherical reflectance and transmittance of leaves based on their known structural and biochemical parameters (listed in Tab. 2). [39]. Inversion of the model allows these parameters to be retrieved from the leaf spectral signatures [41-42]. Although PROSPECT was initially calibrated for measurements carried out with an integrating sphere, those performed with a leaf-clip can also be used [46-47]. The inversion consists in finding the set of structural and biochemical parameters - denoted by the vector $\theta$ - that best simulates the leaf spectral signature measured [42]. This is achieved by successively testing sets of parameters and retaining the one that minimizes the cost function $\mathrm{J}$, defined as:

$$
J(\theta)=\sum_{\lambda_{\text {min }}}^{\lambda_{\text {max }}}\left(R_{\text {meas }}(\lambda)-R_{\text {sim }}(\lambda, \theta)\right)^{2}
$$


where $R_{\text {sim }}$ and $R_{\text {meas }}$ stand for the simulated and measured reflectance, respectively [46-48]. The cost function is computed in the $\left[\lambda_{\min }: \lambda_{\max }\right]$ spectral range [42]. Since only leaf reflectance was measured in our study, we simplified the original function that included transmittance [39].

PROSPECT inversions were first used to estimate the biochemical parameters of the 152 leaves sampled for analysis. Anthocyanins were recently added to the latest version of the model (PROSPECT-D), but their concentrations remained below the detection limit for all the species in our study. We therefore used the PROSPECT- 5 version to perform the inversions as described in [49-51]. The six leaf parameters $\left(N, \mathrm{C}_{\mathrm{ab}}, \mathrm{C}_{\mathrm{xc}}, \mathrm{C}_{\mathrm{bp}}, \mathrm{C}_{\mathrm{w}}\right.$ and $\left.\mathrm{C}_{\mathrm{m}}\right)$ were simultaneously determined through minimization of the cost function (1) over the entire reflective domain (400-2500 nm). ( $N$ corresponds to the leaf structure parameter and mainly influences reflectance in the near-infrared domain $(750-1300 \mathrm{~nm})[39,52-53]$.) Inversions were performed using an iterative optimization approach. Many methods, such as look-up tables and conventional optimization algorithms have been tested for this purpose in previous studies [54-55]. However, these methods can sometimes pose problems. For example, local minima and algorithm nonconvergence lead to biased or inaccurate estimation of biochemical parameters [56-57]. To avoid this, we used the differential evolution (DE) algorithm [58]. The DE combines the advantages of evolutionary and genetic algorithms, which proved to be good candidates for solving inversion problems in remote sensing [59-61]. To avoid extensive computational time, the parameters tested for optimization were constrained to ranges set out in Table 2. For each sample, the best set of leaf parameters was retained. Inversion outputs were validated in two ways. The Root Mean Squared Error (RMSE), the BIAS and the Standard Error of Prediction Corrected from the bias (SEPC) were used to assess the fit between the simulated and the measured spectral signatures on a wavelength-by-wavelength basis [42]. The estimated parameters were compared to biochemical analysis using the same 
metrics and the $\mathrm{R}^{2}$. After validation of the model's performances, we applied the inversion of PROSPECT to the 1620 leaves sampled in order to determine their pigment contents. The same procedure was applied to the leaves sampled on the control site.

Table 2. Parameter bounds used to perform PROSPECT inversions. $\mathrm{C}_{\mathrm{ab}}$ and $\mathrm{C}_{\mathrm{xc}}$ bounds were extended from those of literature to factor in seasonal variations of leaf pigment contents.

\begin{tabular}{rcc} 
Parameter & Unit & Range \\
\hline Leaf structure $(N)$ & - & $1-5$ \\
Chlorophylls $\left(C_{\mathrm{ab}}\right)$ & $\mu \mathrm{g} . \mathrm{cm}^{-2}$ & $1-100$ \\
Carotenoids $\left(\mathrm{C}_{\mathrm{xc}}\right)$ & $\mu \mathrm{g} . \mathrm{cm}^{-2}$ & $1-50$ \\
Brown pigments $\left(\mathrm{C}_{\mathrm{bp}}\right)$ & $\mu \mathrm{g} . \mathrm{cm}^{-2}$ & $0.01-1$ \\
Water $\left(\mathrm{C}_{\mathrm{w}}\right)$ & g.cm & $0.001-0.1$ \\
Dry matter $\left(\mathrm{C}_{\mathrm{m}}\right)$ & g.cm & $0.001-0.1$
\end{tabular}

\subsection{Variability of leaf pigment contents and TPH estimation}

The study then focused on the chlorophyll and carotenoid contents retrieved from PROSPECT inversions. Their seasonal variability was examined for each species using one-way ANOVA and Tukey post-hoc tests to look for significant differences among sampling dates. Pigment contents were then linked to soil TPH concentrations in order to assess their ability to predict the level of contamination. For this purpose, data were divided into 50\% train and 50\% test sets using the Kennard-Stone algorithm, which ensures that representative samples are selected [62-63]. Univariate regression models were adjusted between pigment contents and TPH concentrations on the train set $[26,63]$. The models were then applied to the test set to predict TPH concentrations. This procedure was carried out on the five species successively, on each sampling date. The 
accuracy of the predictions was assessed by calculating the $\mathrm{R}^{2}$ and the RMSE on the train and test sets. In addition, we computed the BIAS, the SEPC and the Residual Predictive Deviation (RPD) on the test sets to complete the accuracy assessment. The RPD is defined as the ratio of the standard deviation of the measured TPH concentration to the RMSE computed between the predicted and measured concentrations [27]. The interpretation of RPD values strongly depends on the context $[27,64]$. RPD values above 2 and 3 are often considered as good and excellent predictions of TPH, respectively, and values below 2 as poor ones. A comprehensive flowchart of the method is presented in Figure 1.

In order to assess the accuracy of our approach, the results were compared to those obtained with approaches directly linking TPH concentrations to leaf reflectance in the VIS, including pigmentrelated vegetation indices (listed in [65]) and partial least square regression (PLSR) with reflectance transformation (derivatives, continuum removal, etc.) [12, 27]. These approaches usually perform well for tracking reflectance changes induced by contaminants $[11-12,25,66]$. The approaches were compared based on the RMSE and RPD values obtained on the test sets. 


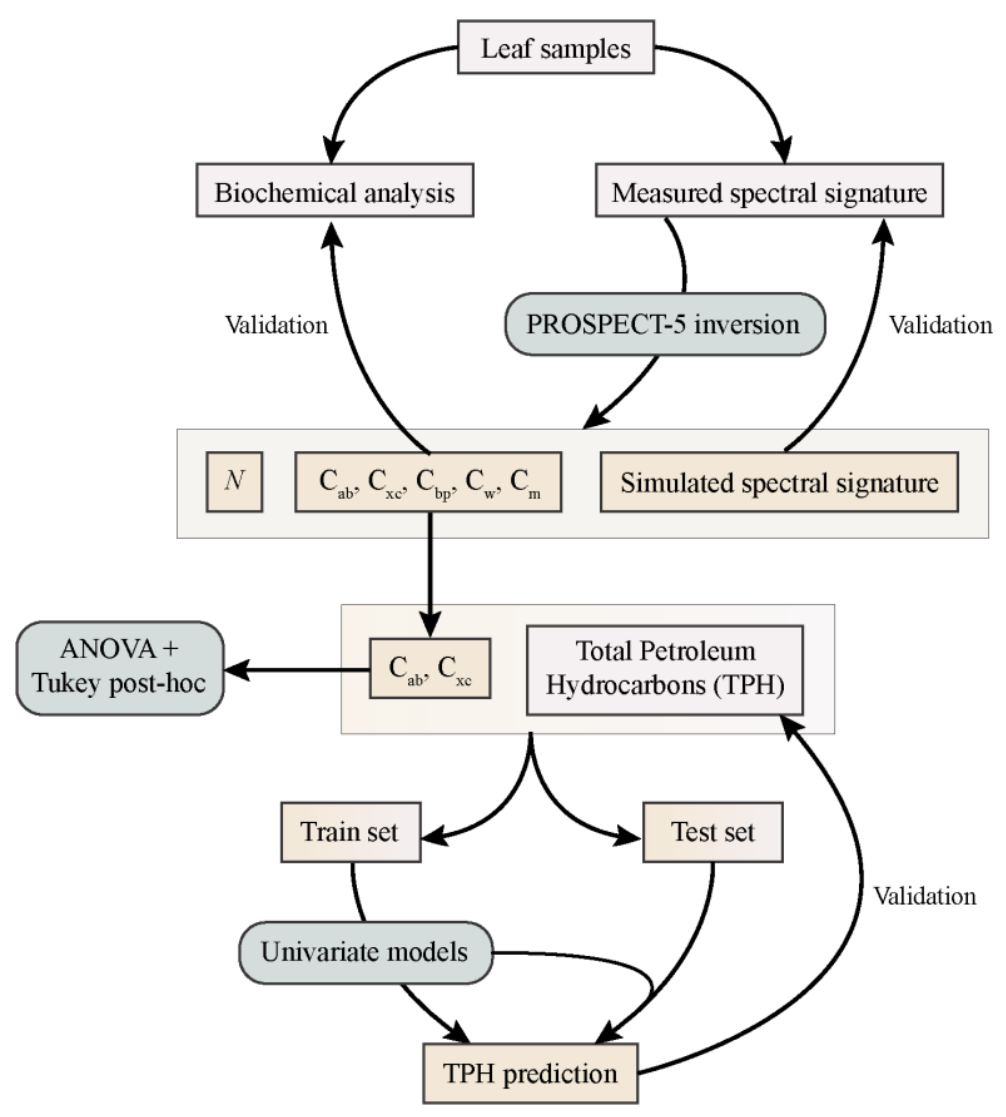

Figure 1. Flowchart of the method presented in this study $\left(N\right.$ : structure parameter, $\mathrm{C}_{\mathrm{ab}}$ :

Chlorophyll content, $\mathrm{C}_{\mathrm{xc}}$ : Carotenoid content, $\mathrm{C}_{\mathrm{bp}}$ : Brown pigments, $\mathrm{C}_{\mathrm{w}}$ : Water, $\mathrm{C}_{\mathrm{m}}$ : Dry matter).

The spectral signatures measured were used to retrieve leaf structural and biochemical parameters using PROSPECT-5 inversions. The estimated parameters were compared to chemical analyses, and the simulated spectral signatures were compared to the measured ones. The estimated pigment contents $\left(\mathrm{C}_{\mathrm{ab}}\right.$ and $\left.\mathrm{C}_{\mathrm{xc}}\right)$ obtained for each season were compared, using ANOVA and Tukey post-hoc tests, and were then used to predict TPH concentrations with the help of univariate models. The predicted TPH concentrations were then compared to those obtained from soil analyses. 


\section{Results and Discussion}

\subsection{Measured spectral signatures}

Since the five species are well-established on the brownfield, they are naturally tolerant to high levels of TPH contamination [25, 32, 67]. Consequently, the leaves did not exhibit marked visible stress symptoms, and their spectral signatures strongly differed from those observed for species highly affected by oil (Fig. 2) [14, 22, 68]. The spectral signatures did however vary temporally and among species during the study.
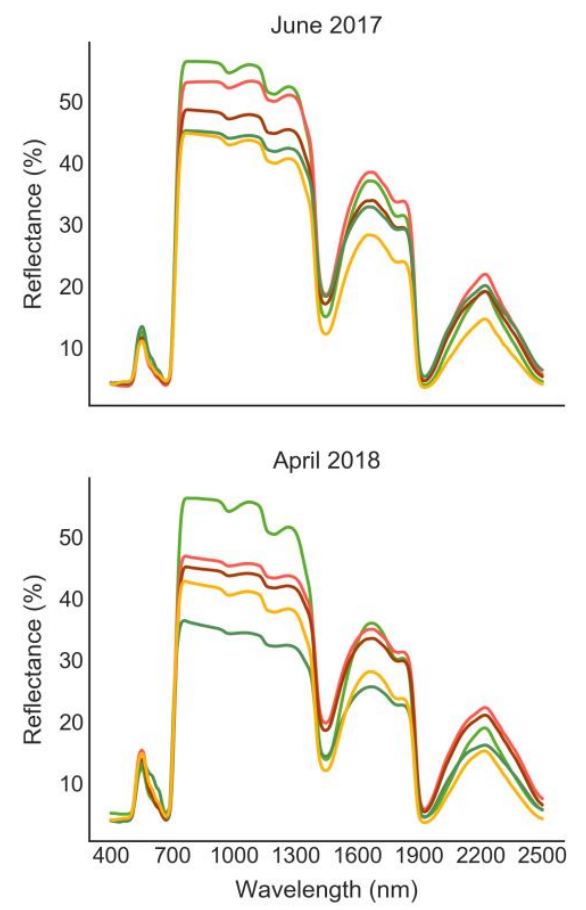
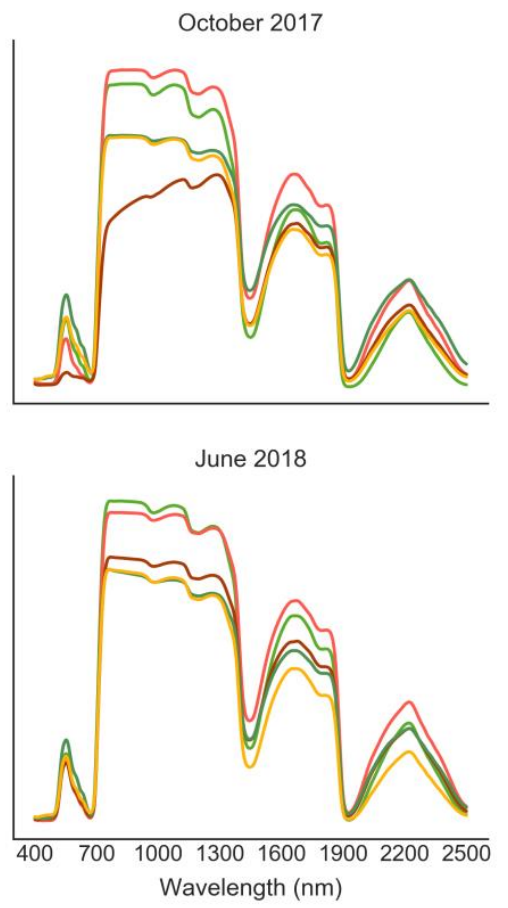
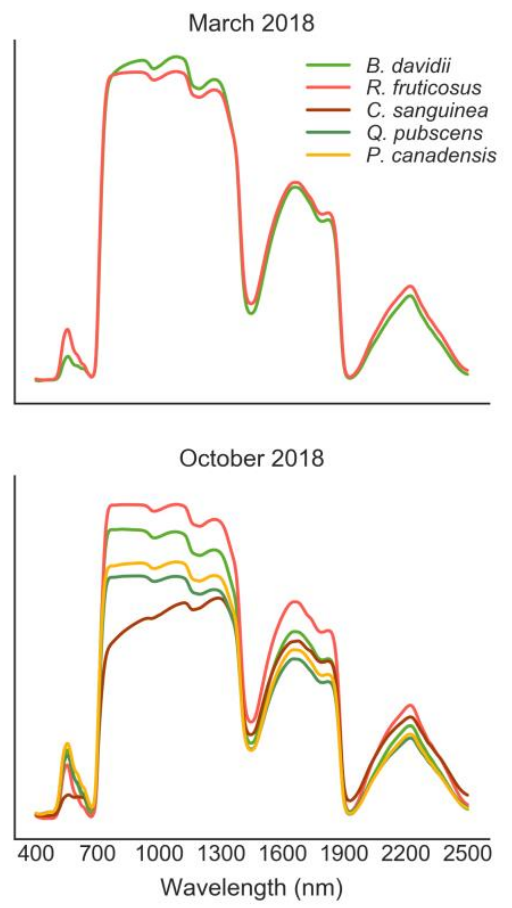

Figure 2. Seasonal evolutions of the mean spectral signatures for the five species on the brownfield.

The variability among the five species highlighted natural differences in leaf anatomy and biochemistry and in sensitivity to TPH exposure [34, 37, 69]. When considering a single species, 
the spectral signatures also varied temporally with season changes, especially in the VIS and the red-edge regions. The summer of 2017 was characterized by repeated heat waves (June), and reflectance was particularly low for all species, varying between 550 and $680 \mathrm{~nm}$ and affecting the red-edge region on the following sampling dates, an indication of changes in leaf pigment contents $[66,70]$. Likewise, reflectance in the near- and short-wave infrared regions was also affected by the seasons, a sign of changes in leaf anatomy and water content [52, 71-72]. All species do not share the same sensitivity to environmental changes from season to season [30-31]. Only small seasonal differences in the leaf reflectance of $R$. fruticosus were observed in relation to the other species. In comparison, $C$. sanguinea underwent substantial changes in October, exhibiting dry blackish leaves with very low VIS reflectance. This unknown symptom differed from the autumn leaf coloration described on Cornus species [73].

The spectral signatures observed on the brownfield are thus the result of leaf anatomy and biochemistry, which are strongly influenced by the species' sensitivities to TPH and the seasons. This explains some of the differences observed among the species and is a significant factor in the prediction of TPH, as described in sections 3.2. to 3.4. 


\subsection{Evaluation of PROSPECT inversions outputs}

\subsubsection{Simulated spectral signatures}

PROSPECT performed well for simulating the spectral signatures of leaves measured during the study. The DE algorithm always converged during inversions and the RMSE computed between the simulated and measured signatures ranged from 0.2 to $2 \%$ reflectance across the entire spectrum for the five species. RMSE, BIAS and SEPC values were consistent with those observed for other datasets $[41-42,74]$. These results are presented in the Supporting Information, along with examples of simulated and measured signatures. Although spectral signatures varied according to the sampling date, the RMSE remained almost unchanged throughout the study. PROSPECT therefore proved efficient for tracking seasonal changes in leaf biochemistry, as suggested in previous studies [30].

\subsubsection{Retrieved biochemical parameters}

Chemical analyses performed on the 152 leaves indicated that PROSPECT accurately estimated biochemical parameters, regardless of the species. An illustration is provided for $R$. fruticosus in Figure 3. The RMSE between the simulated and measured signatures was particularly low in the VIS $(<1.3 \%)$, and resulted in accurate retrieval of chlorophyll and carotenoid contents. Carotenoids were more difficult to estimate because of predominant absorption of chlorophylls in the VIS [42]. However, the RMSE remained below or equal to $1.82 \mu \mathrm{g} . \mathrm{cm}^{-2}$ for these pigments, which still indicated good accuracy. As suggested in previous work, separating carotenoids into carotenes and xanthophylls in PROSPECT might improve estimations, but this is not yet possible in the current version of the model $[42,75]$. Leaf water and dry matter contents were also correctly 
estimated (Fig. 3). All these results were consistent with those obtained on other datasets [46-48, 74-75].
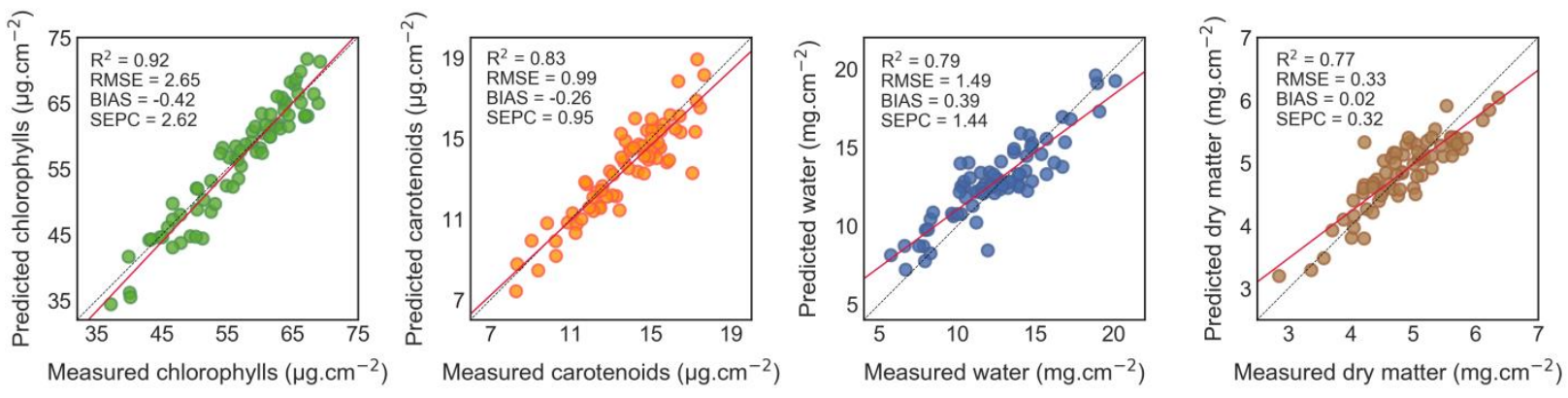

Figure 3. Comparisons of the predicted and measured biochemical parameters of $R$. fruticosus leaves. Water and dry matter contents were expressed in $\mathrm{mg} . \mathrm{cm}^{-2}$ for graphical convenience.

\subsection{Seasonal and interspecific variability of leaf pigments}

The chlorophyll contents estimated throughout study ranged from 9.3 to $90 \mu \mathrm{g} . \mathrm{cm}^{-2}$ on the brownfield, and were higher for all species on the control site with the exception of $B$. davidii. This species was not affected by exposure to TPH and is therefore not a suitable indicator of oil contamination. Detailed results can be found in the Supporting Information section. The reduction in chlorophyll content observed for the other species is commonly described on oil-exposed vegetation $[16,34,70,76]$. Oil contamination reduces water and nutrient availability for plants as well as root uptake capacities $[15,19,21]$. This results in anatomical and biochemical alterations in leaves, including a decrease in pigment contents [16-17]. On the brownfield, chlorophyll content significantly varied among species $(\mathrm{p}<0.05)$. The chlorophyll contents of $R$. fruticosus and $B$. davidii systematically attained the highest values, whereas those of $Q$. pubescens and $P$. canadensis never exceeded $40 \mu \mathrm{g} . \mathrm{cm}^{-2}$ on average. Chlorophyll content also varied significantly 
for each species according to sampling dates $(\mathrm{p}<0.05)$, as suggested by the temporal evolution of spectral signatures (Fig. 2). These variations were however less marked than those of other temperate species [30]. Some smaller differences among species were observed on the control site, indicating natural differences in pigment contents [77-79]. Pigment contents on the brownfield were thus expressed as percentages of those of the control to factor in these differences and to better compare species' sensitivities to TPH exposure (Fig. 4).

The chlorophyll content of $C$. sanguinea leaves taken from the brownfield remained close to that of the control site on all dates, indicating this species' high tolerance to oil contamination (Fig. 4). Q. pubescens was the most sensitive species, regardless of the season. The leaf chlorophyll content almost remained below $60 \%$ of that of the control for this species. R. fruticosus and $P$. canadensis were more tolerant to TPH but their pigment contents still exhibited severe alterations ( $70 \%$ in June and October). This is consistent with the findings of previous studies [24-25]. Such differences in sensitivity among species have already been reported in tropical regions [34], but the factors influencing this sensitivity remain poorly understood. Oil contamination, as found on our study site, is made of a complex cocktail of contaminants - mainly TPH and HM. All these contaminants are likely to affect leaf biochemistry, depending on each species' sensitivity to each of them. R. fruticosus, for example, is particularly tolerant to HM [80-81]. Several species, including $P$. canadensis, developed detoxification mechanisms to protect themselves against the effects of HM and PAH [67, 82-83].

Q. pubescens, P. canadensis and R. fruticosus exhibited a decrease in relative chlorophyll content in April (spring) $(\mathrm{p}<0.05)$, after the appearance of new leaves (Fig. 4). Their sensitivity to TPH exposure was therefore more pronounced during this period, but remained unchanged between June and October in 2017 and 2018, despite important differences in environmental 
conditions among seasons and years. Only $R$. fruticosus and $B$. davidii were found on the brownfield in March 2017, and displayed chlorophyll content very similar to that of the control site.
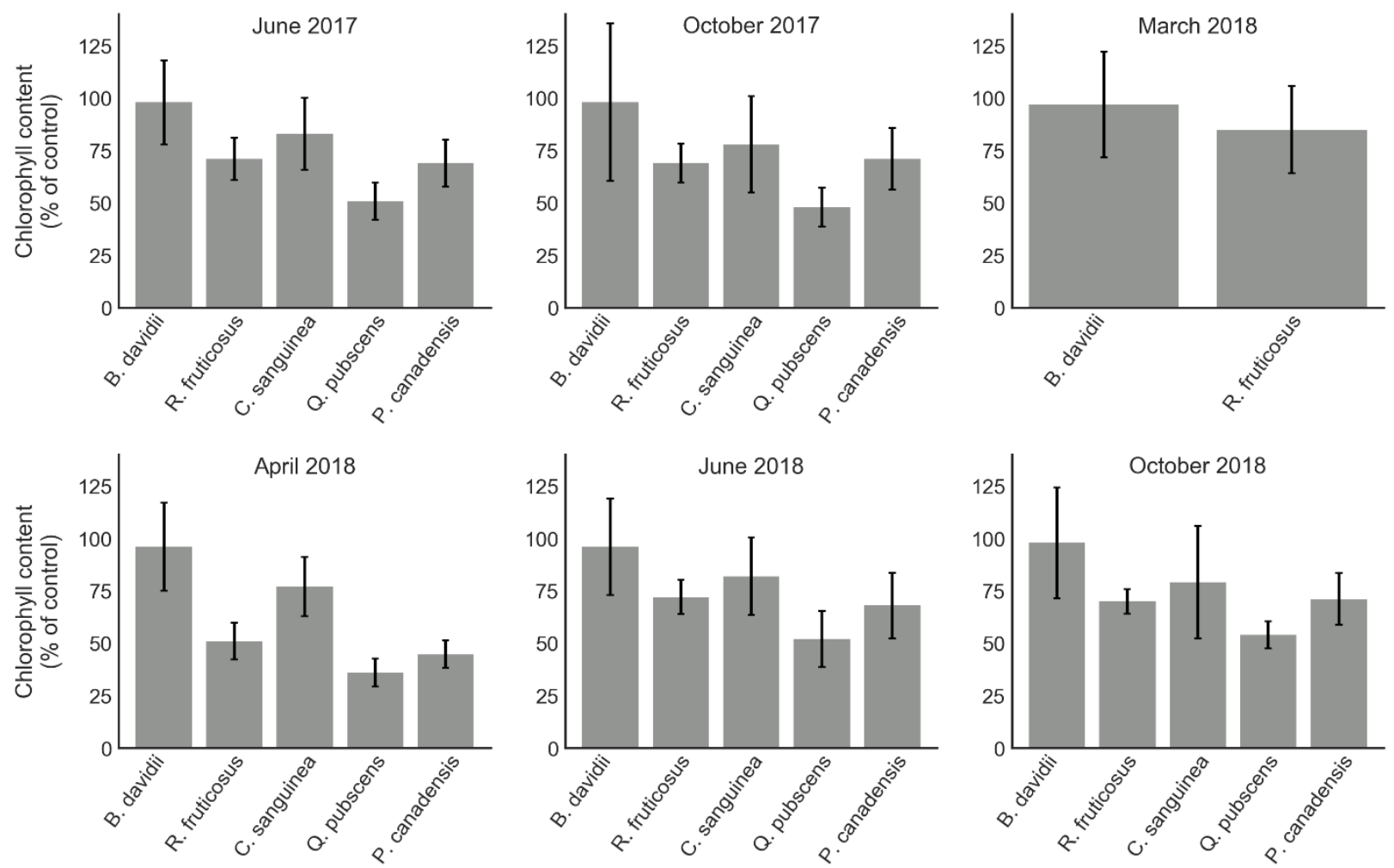

Figure 4. Temporal evolutions of the relative chlorophyll contents of leaves retrieved from PROSPECT inversions on the brownfield, for the five species.

Leaf carotenoid content also varied among species, but did not always vary significantly from one season to the next. These results are shown in the Supporting Information. According to Archetti et al. [29], seasonal variations in leaf color - and thus in leaf reflectance - tend to result from changes in chlorophyll content rather than from carotenoid de novo synthesis. Carotenoid content was up to $60 \%$ lower on the brownfield than on the control site, indicating alterations 
induced by exposure to TPH. The observations made regarding relative chlorophyll content also apply to carotenoids. Previous studies mentioned that carotenoid pigments (i.e. carotenes and xanthophylls) are not affected in the same way by oil contaminants [24-25]. For example, the lutein content might increase when plants are exposed to TPH, but the zeaxanthin content might be altered. Consequently, separating carotenoid pigments would benefit the detection of TPHaffected vegetation, but remains difficult when using hyperspectral spectroscopy [42, 75].

The degree of pigment alteration therefore reflected species' sensitivity to TPH, as suggested by the spectral signatures observed on the brownfield (Fig. 2). Results indicate that this sensitivity varies by season, which is likely to affect TPH predictions, as described in section 3.4.

\subsection{Prediction of TPH from leaf pigments}

Leaf pigment contents from the five species were tested to estimate TPH concentrations in the soil. The results are summarized in Table 3. A strong relationship was observed on the train sets between leaf chlorophyll content and TPH concentrations for $R$. fruticosus, $Q$. pubescens and $P$. canadensis in June and October $\left(\mathrm{R}^{2}\right.$ train $\left.\geq 0.74\right)$. The more contaminated the soil, the lower the chlorophyll content (Fig. 5). This type of plant response has frequently been reported under experimental conditions [15, 17], but never in a natural context and using hyperspectral spectroscopy. Leaf chlorophyll content helped predict TPH concentrations with good (RPD $>2$ ) or excellent (RPD > 3) accuracy, as indicated by the results obtained on the test sets (Tab. 3). Conversely, poor predictions were observed for $B$. davidii, confirming the absence of effects induced by TPH on this species. Over the entire study, the best predictions were obtained with $R$.

fruticosus and Q. pubescens, for which the lowest RMSE - 3.63 and $3.20 \mathrm{~g} \cdot \mathrm{kg}^{-1}$ respectively - and the highest RPD -4.10 and 5.17 respectively - were observed (Fig. 5). Successful predictions 
were also achieved with $P$. canadensis, sometimes even exceeding those of the other species, such as in October $2017\left(\mathrm{RMSE}=5.86 \mathrm{~g} \cdot \mathrm{kg}^{-1}\right.$ and RPD $\left.=3.04\right)$. Inaccuracies in pigment estimation also affected TPH predictions. For example, the RMSE observed for chlorophylls on R. fruticosus (2.62 $\mu$ g.cm ${ }^{-2}$, Fig. 3) was greater than the pigment variations for TPH concentrations between 40 and 60 g.kg-1 (Fig. 5). In that sense, making improvements to PROSPECT, including the separation of chlorophylls a and b, might help improve TPH predictions [75].

Predictions were more accurate for TPH concentrations of less than $30 \mathrm{~g} \cdot \mathrm{kg}^{-1}$, because small variations rapidly induced changes in chlorophyll content (Fig. 5). Above 30 g.kg-1 , TPH were more difficult to predict as the chlorophyll content tended to stabilize. This type of difficulty might also arise outside of the range studied. Lethal concentrations of TPH would become impossible to predict for example. Likewise, predictions might be difficult with R. fruticosus, Q. pubescens and P. canadensis at very low concentrations ( $\mu \mathrm{g}$ to $\left.\mathrm{mg} \cdot \mathrm{kg}^{-1}\right)$, because little or no pigment alterations are expected for these species. At such low concentrations, the use of a species more sensitive to TPH might however make predictions possible [26]. 
Table 3. Assessment of Total Petroleum Hydrocarbons (TPH) in the soil predicted from leaf chlorophyll content on the train and test datasets. RMSE, BIAS and SEPC are given in $\mathrm{g} \cdot \mathrm{kg}^{-1}$ (abs: absent from the site). The best prediction results are marked in bold.

\begin{tabular}{|c|c|c|c|c|c|c|c|c|}
\hline Species & Season & \multicolumn{2}{|c|}{ train } & \multicolumn{5}{|c|}{ test } \\
\hline \multirow{7}{*}{ B. davidii } & & $\mathrm{R}^{2}$ & RMSE & $\mathrm{R}^{2}$ & RMSE & BIAS & SEPC & RPD \\
\hline & June 2017 & 0.06 & 16.78 & 0.04 & 16.24 & 3.04 & 15.95 & 1.00 \\
\hline & October 2017 & 0.05 & 19.27 & 0.07 & 18.14 & -4.40 & 17.60 & 0.90 \\
\hline & March 2018 & 0.01 & 17.01 & 0.03 & 16.47 & -10.35 & 12.81 & 0.99 \\
\hline & April 2018 & 0.01 & 21.13 & 0.02 & 20.01 & -5.50 & 19.24 & 0.81 \\
\hline & June 2018 & 0.04 & 16.18 & 0.07 & 15.98 & 0.12 & 15.98 & 1.02 \\
\hline & October 2018 & 0.01 & 19.04 & 0.02 & 17.76 & -1.31 & 17.71 & 0.92 \\
\hline \multirow{6}{*}{ R. fruticosus } & June 2017 & 0.89 & 5.54 & 0.94 & 3.63 & -0.21 & 3.62 & 4.10 \\
\hline & October 2017 & 0.61 & 10.44 & 0.74 & 7.64 & 1.56 & 7.48 & 1.95 \\
\hline & March 2018 & 0.02 & 15.47 & 0.19 & 17.05 & -0.93 & 17.02 & 0.87 \\
\hline & April 2018 & 0.05 & 13.31 & 0.12 & 18.31 & -4.68 & 17.70 & 0.81 \\
\hline & June 2018 & 0.75 & 8.56 & 0.78 & 6.64 & -0.58 & 6.62 & 2.24 \\
\hline & October 2018 & 0.79 & 6.50 & 0.77 & 8.28 & -0.35 & 8.27 & 1.80 \\
\hline \multirow{6}{*}{ C. sanguinea } & June 2017 & 0.01 & 15.71 & 0.01 & 15.75 & 1.93 & 15.63 & 1.02 \\
\hline & October 2017 & 0.03 & 17.81 & 0.04 & 17.20 & 0.32 & 17.19 & 0.93 \\
\hline & March 2018 & abs. & abs. & abs. & abs. & abs. & abs. & abs. \\
\hline & April 2018 & 0.01 & 14.24 & 0.02 & 17.33 & -1.34 & 17.28 & 0.92 \\
\hline & June 2018 & 0.01 & 15.88 & 0.01 & 15.98 & -0.03 & 15.98 & 1.00 \\
\hline & October 2018 & 0.04 & 18.39 & 0.01 & 17.45 & 0.86 & 17.43 & 0.92 \\
\hline \multirow{6}{*}{ Q. pubescens } & June 2017 & 0.78 & 8.41 & 0.85 & 5.70 & 2.24 & 5.24 & 2.89 \\
\hline & October 2017 & 0.66 & 10.09 & 0.86 & 5.82 & 0.65 & 5.79 & 2.83 \\
\hline & March 2018 & abs. & abs. & abs. & abs. & abs. & abs. & abs. \\
\hline & April 2018 & 0.01 & 15.80 & 0.03 & 17.94 & 0.84 & 17.92 & 0.92 \\
\hline & June 2018 & 0.72 & 8.93 & 0.96 & 3.20 & -0.20 & 3.19 & 5.17 \\
\hline & October 2018 & 0.57 & 11.82 & 0.83 & 5.88 & 0.66 & 5.85 & 2.80 \\
\hline \multirow{6}{*}{ P. canadensis } & June 2017 & 0.61 & 11.03 & 0.80 & 6.85 & 0.22 & 6.85 & 2.60 \\
\hline & October 2017 & 0.76 & 7.62 & 0.89 & 5.86 & 0.67 & 5.82 & 3.04 \\
\hline & March 2018 & abs. & abs. & abs. & abs. & abs. & abs. & abs. \\
\hline & April 2018 & 0.05 & 16.91 & 0.13 & 16.26 & 5.64 & 15.25 & 1.09 \\
\hline & June 2018 & 0.62 & 10.70 & 0.75 & 7.83 & -1.16 & 7.74 & 2.27 \\
\hline & October 2018 & 0.74 & 8.93 & 0.81 & 6.62 & -3.18 & 5.81 & 2.69 \\
\hline
\end{tabular}


There was no observable relationship between leaf chlorophyll content and TPH concentrations in March and April for R. fruticosus, Q. pubescens and P. canadensis (Tab. 3). Consequently, the predictions of TPH on these dates were poor. The leaf chlorophyll content of $R$. fruticosus was the same as that of the control site in March (Fig. 4), meaning that the species was thus not affected by TPH, which explains the inaccurate predictions. April was characterized by the appearance of new leaves in the three species, along with the most pronounced alteration in leaf chlorophyll content. The plants' sensitivity to TPH exposure is particularly pronounced in the growing stages [12, 84]. As a result, chlorophyll content in April 2017 displayed similar alterations regardless of the contamination level, which had an impact on TPH predictions. A similar response was observed for C. sanguinea leaves over the entire study (Tab. 3). In this case, chlorophyll content made it possible to detect but not to quantify TPH (RMSE $>15$ g. $\left.\mathrm{kg}^{-1}, \mathrm{RPD}<1.10\right)$. Consequently, the relationship between the leaf chlorophyll content and TPH concentrations observed for three out of the five species appeared after the growing period (April). This temporal pattern is of critical importance for the long-term monitoring of oil activities, as it shows that a single campaign carried out at the right time can be sufficient to assess the level of soil contamination. 


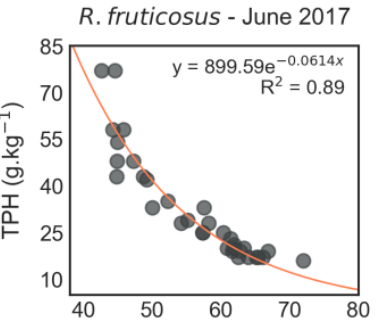

Predicted chlorophylls $\left(\mu \mathrm{g} . \mathrm{cm}^{-2}\right)$

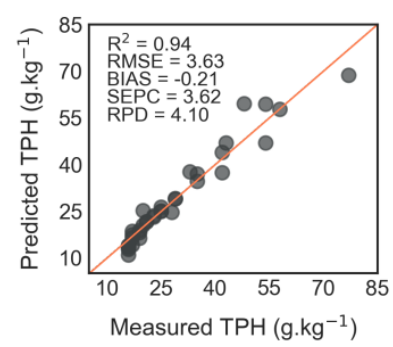

Q. pubscens - June 2018

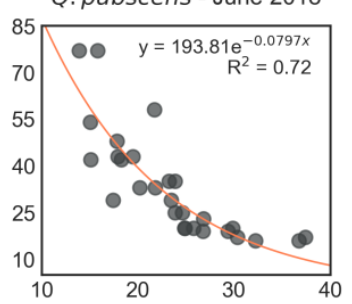

Predicted chlorophylls $\left(\mu \mathrm{g} . \mathrm{cm}^{-2}\right)$

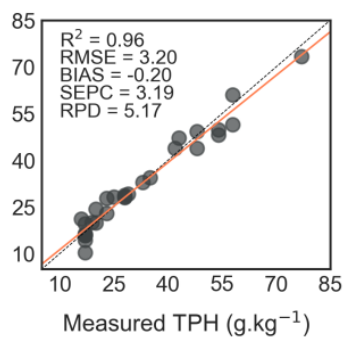

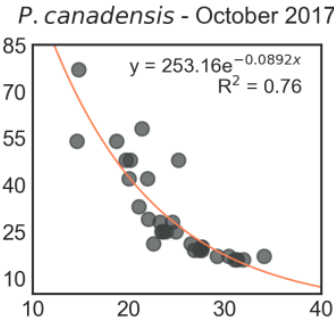

Predicted chlorophylls ( $\mu$ g. $\left.\mathrm{cm}^{-2}\right)$

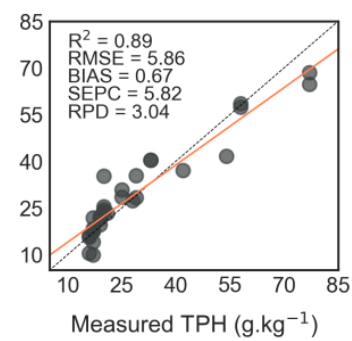

C. sanguinea - June 2017

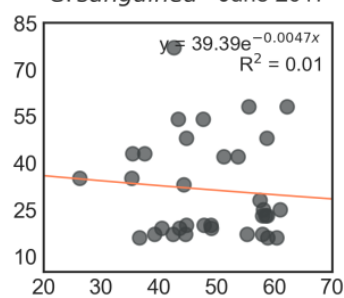

Predicted chlorophylls $\left(\mu \mathrm{g} . \mathrm{cm}^{-2}\right)$

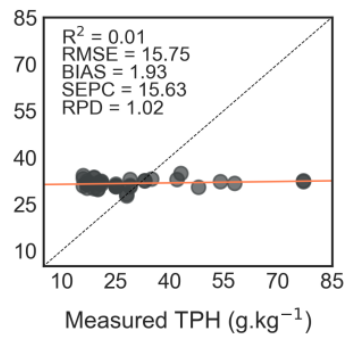

Figure 5. Relationship between predicted leaf chlorophyll content and Total Petroleum

Hydrocarbons (TPH) in the soil on the train datasets (top figures) and comparisons between predicted and measured TPH on the test datasets (bottom figures).

Leaf chlorophyll and carotenoid contents are usually well-correlated [41-42]. However, the exposure of plants to TPH altered this correlation. The relationship between carotenoid content and TPH was weaker than for chlorophyll content $\left(\mathrm{R}^{2} \leq 0.60\right)$ and made predictions more difficult. The results obtained with $R$. fruticosus, $Q$. pubescens and $P$. canadensis were very similar. The best RMSE was observed with $R$. fruticosus (8.31 g. $\mathrm{kg}^{-1}$ ), but represented poor predictions nonetheless (RPD < 2) (see Supporting Information). As discussed above, the contrasting effects of TPH on carotenoid pigments might have altered the relationship between leaf carotenoid content and TPH concentrations and therefore contributed to inaccuracies. Predictions might be greatly improved by separating carotenoid pigments and focusing on particular ones.

When compared to the proposed approach, vegetation indices and PLSR did not give any more accurate TPH predictions for $B$. davidii and $C$. sanguinea, confirming that these species are not 
suitable for predicting TPH. These results are presented in the Supporting Information. Predictions were better than those obtained with carotenoid content in the other species, but never reached those achieved with chlorophyll content. RMSE never dropped below $5.86 \mathrm{~g} \cdot \mathrm{kg}^{-1}$ and RPD never exceeded 2.57. Consequently, our approach outperformed vegetation indices and PLSR. One possible explanation is that in the VIS, leaf optical properties are mainly influenced by chlorophylls, and to a lesser extent by carotenoids - and other pigments - that were less correlated to TPH concentrations in our study [35, 37]. Therefore, TPH predictions using vegetation indices and PLSR suffered from the influence of carotenoids, which introduced inaccuracies. Conversely, the proposed approach using PROSPECT made it possible to isolate chlorophyll content, thereby improving TPH predictions.

\section{Conclusion}

This study demonstrates that TPH concentrations in oil-contaminated soils can be estimated from leaf optical properties using PROSPECT. The model performed well for simulating the spectral signatures and for retrieving pigment contents of leaves from exposed vegetation. Leaf chlorophyll content was strongly linked to TPH concentrations and allowed accurate predictions of these contaminants. The response of carotenoid pigments was complex and made predictions more difficult. Our approach was more effective than vegetation indices and PLSR, thanks to pigment separation. This study reveals that the accuracy of predictions strongly varies among species, because of their different sensitivities to TPH exposure. Three out of the five species studied (R. fruticosus, $Q$. pubescens and $P$. canadensis) were successful in predicting TPH. Moreover, the sensitivity of a single species also varies throughout the year, according to season 
changes. Changes in the species' sensitivity, during the growing period (April) for example, affect TPH predictions.

Considering these factors, the proposed approach can be used as a reliable tool for assessing soil contamination on oil production facilities. In the future, the approach could be applied to airborne images with high spatial and spectral resolutions for monitoring large industrial areas with dense vegetation. For this purpose, the combination of the PROSPECT and SAIL models (called PROSAIL [40]), which takes into account canopy architecture, Leaf Area Index (LAI) and viewing geometry, will be addressed in further research.

\section{Acknowledgements}

This work was performed in the frame of the NAOMI project between TOTAL and the ONERA, with the support of the Ecolab and Dynafor research units of Toulouse. The authors gratefully acknowledge E. Buffan-Dubau, D. Lambrigot and O. Berseille for their assistance in pigment analysis, and E. Hannan for correcting the manuscript.

Declarations of interest: None.

Funding: Financial support of this work was provided by TOTAL.

\section{References}

[1] S. Datta, S. Sarkar, A review on different pipeline fault detection methods, J. Loss Prev. Process Ind. 41 (2016) 97-106. https://doi.org/10.1016/j.jlp.2016.03.010 
[2] M.N. Jha, J. Levy, Y. Gao, Advances in Remote Sensing for Oil Spill Disaster Management: State-of-the-Art Sensors Technology for Oil Spill Surveillance, Sensors 8 (2008) 236-255. https://doi.org/10.3390/s8010236

[3] A. Shukla, H. Karki, Application of robotics in onshore oil and gas industry-A review Part I, Rob. Auton. Syst. 75 (2016) 490-507. https://doi.org/10.1016/j.robot.2015.09.012

[4] F. Barraza, L. Maurice, G. Uzu, S. Becerra, F. López, V. Ochoa-Herrera, J. Ruales, E. Schreck, Distribution, contents and health risk assessment of metal(loid)s in small-scale farms in the Ecuadorian Amazon: An insight into impacts of oil activities, Sci. Total Environ. 622-623 (2018) 106-120. https://doi.org/10.1016/j.scitotenv.2017.11.246

[5] R.E. Correa Pabón, C.R. de Souza Filho, W.J. de Oliveira, Reflectance and imaging spectroscopy applied to detection of petroleum hydrocarbon pollution in bare soils, Sci. Total Environ. 649 (2019) 1224-1236. https://doi.org/10.1016/j.scitotenv.2018.08.231

[6] Y. Perrodin, C. Boillot, R. Angerville, G. Donguy, E. Emmanuel, Ecological risk assessment of urban and industrial systems: A review, Sci. Total Environ. 409 (2011) 5162 5176. https://doi.org/10.1016/j.scitotenv.2011.08.053

[7] S. Khanna, M.J. Santos, S.L. Ustin, K. Shapiro, P.J. Haverkamp, M. Lay, Comparing the potential of multispectral and hyperspectral data for monitoring oil spill impact, Sensors 18(558) (2018). https://doi.org/10.3390/s18020558

[8] R.D.P.M. Scafutto, C.R. de Souza Filho, B. Rivard, Characterization of mineral substrates impregnated with crude oils using proximal infrared hyperspectral imaging, Remote Sens. Environ. 179 (2016) 116-130. https://doi.org/10.1016/j.rse.2016.03.033

[9] R.E. Correa Pabón, C.R. de Souza Filho, Spectroscopic characterization of red latosols contaminated by petroleum-hydrocarbon and empirical model to estimate pollutant content and type, Remote Sens. Environ. 175 (2016) 323-336. https://doi.org/10.1016/j.rse.2016.01.005

[10] R.D.P.M. Scafutto, C.R. de Souza Filho, W.J. de Oliveira, Hyperspectral remote sensing detection of petroleum hydrocarbons in mixtures with mineral substrates: Implications for onshore exploration and monitoring, ISPRS J. Photogramm. Remote Sens. 128 (2017) 146157. https://doi.org/10.1016/j.isprsjprs.2017.03.009

[11] P. Arellano, K. Tansey, H. Balzter, D.S. Boyd, Detecting the effects of hydrocarbon pollution in the Amazon forest using hyperspectral satellite images, Environ. Pollut. 205 (2015) 225-239. https://doi.org/10.1016/j.envpol.2015.05.041

[12] G. Lassalle, A. Credoz, R. Hédacq, S. Fabre, D. Dubucq, A. Elger, Assessing Soil Contamination Due to Oil and Gas Production Using Vegetation Hyperspectral Reflectance, Environ. Sci. Technol. 52 (2018) 1756-1764. https://doi.org/10.1021/acs.est.7b04618 
[13] M.F. Noomen, H.M.A. van der Werff, F.D. van der Meer, Spectral and spatial indicators of botanical changes caused by long-term hydrocarbon seepage, Ecol. Inform. 8 (2012) 55-64. https://doi.org/10.1016/j.ecoinf.2012.01.001

[14] I.D. Sanches, C.R. Souza Filho, L.A. Magalhães, G.C.M. Quitério, M.N. Alves, W.J. de Oliveira, Assessing the impact of hydrocarbon leakages on vegetation using reflectance spectroscopy, ISPRS J. Photogramm. Remote Sens. 78 (2013a) 85-101. https://doi.org/10.1016/j.isprsjprs.2013.01.007

[15] H. ur R. Athar, S. Ambreen, M. Javed, M. Hina, S. Rasul, Z.U. Zafar, H. Manzoor, C.C. Ogbaga, M. Afzal, F. Al-Qurainy, M. Ashraf, Influence of sub-lethal crude oil concentration on growth, water relations and photosynthetic capacity of maize (Zea mays L.) plants, Environ. Sci. Pollut. Res. 23 (2016) 18320-18331. https://doi.org/10.1007/s11356-016-6976-7

[16] A.G. Balliana, B.B. Moura, R.C. Inckot, C. Bona, Development of Canavalia ensiformis in soil contaminated with diesel oil, Environ. Sci. Pollut. Res. 24 (2017) 979-986. https://doi.org/10.1007/s11356-016-7674-1

[17] P. Baruah, R.R. Saikia, P.P. Baruah, S. Deka, Effect of crude oil contamination on the chlorophyll content and morpho-anatomy of Cyperus brevifolius (Rottb.) Hassk., Environ. Sci. Pollut. Res. 21 (2014) 12530-12538. https://doi.org/10.1007/s11356-014-3195-y

[18] G. Han, B.X. Cui, X.X. Zhang, K.R. Li, The effects of petroleum-contaminated soil on photosynthesis or Amorpha fruticosa seedlings, Int. J. Environ. Sci. Technol 13 (2016) 2383-2392. https://doi.org/10.1007/s13762-016-1071-7

[19] A. Balasubramaniyam, P.J. Harvey, Scanning electron microscopic investigations of root structural modifications arising from growth in crude oil-contaminated sand, Environ. Sci. Pollut. Res. 21 (2014) 12651-12661. https://doi.org/10.1007/s11356-014-3138-7

[20] I. Kisic, S. Mesic, F. Basic, V. Brkic, M. Mesic, G. Durn, Z. Zgorelec, L. Bertovic, The effects of drilling fluids and crude oil on some chemical characteristics of soil and crops, Geoderma 149 (2009) 209-216. https://doi.org/10.1016/j.geoderma.2008.11.041

[21] M. Nie, M. Lu, Q. Yang, X.D. Zhang, M. Xiao, L.F. Jiang, J. Yang, C.M. Fang, J.K. Chen, B. Li, Plants' use of different nitrogen forms in response to crude oil contamination, Environ. Pollut. 159 (2011) 157-163. https://doi.org/10.1016/j.envpol.2010.09.013

[22] P.H. Rosso, J.C. Pushnik, M. Lay, S.L. Ustin, Reflectance properties and physiological responses of Salicornia virginica to heavy metal and petroleum contamination, Environ. Pollut. 137 (2005) 241-252. https://doi.org/10.1016/j.envpol.2005.02.025

[23] P. Arellano, K. Tansey, H. Balzter, D.S. Boyd, Field spectroscopy and radiative transfer modelling to assess impacts of petroleum pollution on biophysical and biochemical 
parameters of the Amazon rainforest, Environ. Earth Sci. 76 (2017b) 1-14.

https://doi.org/10.1007/s12665-017-6536-6

[24] G. Lassalle, A. Credoz, S. Fabre, R. Hédacq, D. Dubucq, A. Elger, Hyperspectral signature analysis of three plant species to long-term hydrocarbon and heavy metal exposure, in: Proceedings of SPIE - The International Society for Optical Engineering (2017). https://doi.org/10.1117/12.2277709

[25] G. Lassalle, S. Fabre, A. Credoz, R. Hédacq, P. Borderies, G. Bertoni, T. Erudel, E. BuffanDubau, D. Dubucq, A. Elger, Detection and discrimination of various oil-contaminated soils using vegetation reflectance, Sci. Tot. Environ. 655 (2019) 1113-1124. https://doi.org/10.1016/j.scitotenv.2018.11.314

[26] L. Zhu, X. Zhao, L. Lai, J. Wang, L. Jiang, J. Ding, N. Liu, Y. Yu, J. Li, N. Xiao, Y. Zheng, G.M. Rimmington, Soil TPH concentration estimation using vegetation indices in an oil polluted area of eastern China, PLoS One 8 (2013) https://doi.org/10.1371/journal.pone.0054028

[27] T. Shi, H. Liu, J. Wang, Y. Chen, T. Fei, G. Wu, Monitoring arsenic contamination in agricultural soils with reflectance spectroscopy of rice plants, Environ. Sci. Technol. 48 (2014) 6264-6272. https://doi.org/10.1021/es405361n

[28] C. Zhou, S. Chen, Y. Zhang, J. Zhao, D. Song, D. Liu, Evaluating metal effects on the reflectance spectra of plant leaves during different seasons in post-mining areas, China, Remote Sens. 10 (2018). https://doi.org/10.3390/rs10081211

[29] M. Archetti, T.F. Döring, S.B. Hagen, N.M. Hughes, S.R. Leather, D.W. Lee, S. LevYadun, Y. Manetas, H.J. Ougham, P.G. Schaberg, H. Thomas, Unravelling the evolution of autumn colours: an interdisciplinary approach, Trends Ecol. Evol. 24 (2009) 166-173. https://doi.org/10.1016/j.tree.2008.10.006

[30] V. Demarez, Seasonal variation of leaf chlorophyll content of a temperate forest. Inversion of the PROSPECT model. Int. J. Remote Sens. 20 (1999) 879-894. https://doi.org/10.1080/014311699212975

[31] C.D. Stylinski, J.A. Gamon, W.C. Oechel, Seasonal patterns of reflectance indices, carotenoid pigments and photosynthesis of evergreen chaparral species, Oecologia 131 (2002) 366-374. https://doi.org/10.1007/s00442-002-0905-9

[32] A. Credoz, R. Hédacq, C. Barreau, D. Dubucq, Experimental study of hyperspectral responses of plants grown on mud pit soil, in: Proceedings of SPIE - The International Society for Optical Engineering (2016) 10005. https://doi.org/10.1117/12.2239606

[33] E.J. Emengini, F.C. Ezeh, N. Chigbu, Comparative Analysis of Spectral Responses of Varied Plant Species to Oil Stress, International Journal of Scientific \& Engineering Research, 4(6) (2013b) 1421-1427. 
[34] P. Arellano, K. Tansey, H. Balzter, M. Tellkamp, Plant family-specific impacts of petroleum pollution on biodiversity and leaf chlorophyll content in the Amazon rainforest of Ecuador, PLoS One 12 (2017a) 1-18. https://doi.org/10.1371/journal.pone.0169867

[35] G.A. Blackburn, Quantifying chlorophylls and carotenoids at leaf and canopy scales, Remote Sens. Environ. 66 (1998) 273-285. https://doi.org/10.1016/S0034-4257(98)00059-5

[36] A.A. Gitelson, M.N. Merzlyak, H.K. Lichtenthaler, Detection of red edge position and chlorophyll content by reflectance measurements near 700 nm, J. Plant Physiol. 148 (1996) 501-508. https://doi.org/10.1016/S0176-1617(96)80285-9

[37] D.A. Sims, J.A. Gamon, Relationships between leaf pigment content and spectral reflectance across a wide range of species, leaf structures and developmental stages, Remote Sens. Environ. 81 (2002) 337-354. https://doi.org/10.1016/S0034-4257(02)00010-X

[38] J. Verrelst, G. Camps-Valls, J. Muñoz-Marí, J.P. Rivera, F. Veroustraete, J.G.P.W. Clevers, J. Moreno, Optical remote sensing and the retrieval of terrestrial vegetation bio-geophysical properties - A review, ISPRS J. Photogramm. Remote Sens. 108 (2015) 273-290. https://doi.org/10.1016/j.isprsjprs.2015.05.005

[39] S. Jacquemoud, F. Baret, PROSPECT: A model of leaf optical properties spectra, Remote Sens. Environ. 34 (1990) 75-91. https://doi.org/10.1016/0034-4257(90)90100-Z

[40] S. Jacquemoud, W. Verhoef, F. Baret, C. Bacour, P.J. Zarco-Tejada, G.P. Asner, C. François, S.L. Ustin, PROSPECT + SAIL models: A review of use for vegetation characterization, Remote Sens. Environ. 113 (2009) S56-S66. https://doi.org/10.1016/j.rse.2008.01.026

[41] J. Jiang, A. Comar, P. Burger, P. Bancal, M. Weiss, F. Baret, Estimation of leaf traits from reflectance measurements: Comparison between methods based on vegetation indices and several versions of the PROSPECT model, Plant Methods 14 (2018) 1-16. https://doi.org/10.1186/s13007-018-0291-x

[42] J.B. Féret, C. François, G.P. Asner, A.A. Gitelson, R.E. Martin, L.P.R. Bidel, S.L. Ustin, G. le Maire, S. Jacquemoud, PROSPECT-4 and 5: Advances in the leaf optical properties model separating photosynthetic pigments, Remote Sens. Environ. 112 (2008) 3030-3043. https://doi.org/10.1016/j.rse.2008.02.012

[43] J.B. Féret, A.A. Gitelson, S.D. Noble, S. Jacquemoud, PROSPECT-D: Towards modeling leaf optical properties through a complete lifecycle, Remote Sens. Environ. 193 (2017) 204-215. https://doi.org/10.1016/j.rse.2017.03.004

[44] M.T. Yilmaz, E.R. Hunt, T.J. Jackson, Remote sensing of vegetation water content from equivalent water thickness using satellite imagery, Remote Sens. Environ. 112 (2008) 2514-2522. https://doi.org/10.1016/j.rse.2007.11.014 
[45] N.J. Diepens, E. Buffan-Dubau, H. Budzinski, J. Kallerhoff, G. Merlina, J. Silvestre, I. Auby, N. Tapie, A. Elger, Toxicity effects of an environmental realistic herbicide mixture on the seagrass Zostera noltei, Environ. Pollut. 222 (2017) 393-403. https://doi.org/10.1016/j.envpol.2016.12.021

[46] P. Li, Q. Wang, Retrieval of leaf biochemical parameters using PROSPECT inversion: A new approach for alleviating ill-posed problems, IEEE Trans. Geosci. Remote Sens. 49 (2011) 2499-2506. https://doi.org/10.1109/TGRS.2011.2109390

[47] R. Sonobe, T. Sano, H. Horie, Using spectral reflectance to estimate leaf chlorophyll content of tea with shading treatments, Biosyst. Eng. 175 (2018) 168-182. https://doi.org/10.1016/j.biosystemseng.2018.09.018

[48] J. Sun, S. Shi, J. Yang, L. Du, W. Gong, B. Chen, S. Song, Analyzing the performance of PROSPECT model inversion based on different spectral information for leaf biochemical properties retrieval, ISPRS J. Photogramm. Remote Sens. 135 (2018) 74-83. https://doi.org/10.1016/j.isprsjprs.2017.11.010

[49] F. Qiu, J.M. Chen, W. Ju, J. Wang, Q. Zhang, M. Fang, Improving the PROSPECT model to consider anisotropic scattering of leaf internal materials and its use for retrieving leaf biomass in fresh leaves, IEEE Trans. Geosci. Remote Sens. 56 (2018) 3119-3136. https://doi.org/10.1109/TGRS.2018.2791930

[50] Z. Wang, A.K. Skidmore, T. Wang, R. Darvishzadeh, J. Hearne, Applicability of the PROSPECT model for estimating protein and cellulose + lignin in fresh leaves, Remote Sens. Environ. 168 (2015) 205-218. https://doi.org/10.1016/j.rse.2015.07.007

[51] K. Berger, C. Atzberger, M. Danner, G. D’Urso, W. Mauser, F. Vuolo, T. Hank, Evaluation of the PROSAIL model capabilities for future hyperspectral model environments: A review study, Remote Sens. 10(85) (2018).

[52] J.M. Ourcival, R. Joffre, S. Rambal, Exploring the relationships between reflectance and anatomical and biochemical properties in Quercus ilex leaves, New Phytol. 143 (1999) 351364. https://doi.org/10.1046/j.1469-8137.1999.00456.x

[53] M.R. Slaton, E.R. Hunt, W.K. Smith, Estimating near-infrared leaf reflectance from leaf structural characteristics, Am. J. Bot. 88 (2001) 278-284. https://doi.org/10.2307/2657019

[54] R. Darvishzadeh, A. Skidmore, M. Schlerf, C. Atzberger, Inversion of a radiative transfer model for estimating vegetation LAI and chlorophyll in a heterogeneous grassland, Remote Sens. Environ. 112 (2008) 2592-2604. https://doi.org/10.1016/j.rse.2007.12.003

[55] P.J. Zarco-Tejada, J.R. Miller, J. Harron, B. Hu, T.L.Noland, N. Goel, G.H. Mohammed, P. Sampson, Needle chlorophyll content estimation through model inversion using hyperspectral data from boreal conifer forest canopies, Remote Sens. Environ. 89 (2004) 189-199. https://doi.org/10.1016/j.rse.2002.06.002 
[56] Y. Altmann, A. Halimi, N. Dobigeon, J.Y. Tourneret, Supervised nonlinear spectral unmixing using a postnonlinear mixing model for hyperspectral imagery, IEEE Trans. Image Process. 21 (2012) 3017-3025. https://doi.org/10.1109/TIP.2012.2187668

[57] S. Jacquemoud, F. Baret, B. Andrieu, F.M. Danson, K. Jaggard, Extraction of Vegetation Biophysical Parameters by Inversion of the PROSPECT + SAIL Models on Sugar Beet Canopy Reflectance Data. Application to TM and AVIRIS Sensors, Remote Sens. Environ. 52 (1995) 163-172.

[58] R. Storn, K. Price, Differential Evolution - A Simple and Efficient Heuristic for Global Optimization over Continuous Spaces. J. Glob. Optim. 11 (1997) 341-359. https://doi.org/10.1023/A:1008202821328

[59] S. Das, S.S. Mullick, P.N. Suganthan, Recent advances in differential evolution-An updated survey, Swarm Evol. Comput. 27 (2016) 1-30. https://doi.org/10.1016/j.swevo.2016.01.004

[60] A. Ghosh, Datta A., S. Ghosh, Self-adaptive differential evolution for feature selection in hyperspectral image data. Appl. Soft Comput. J. 13 (2013) 1969-1977. https://doi.org/10.1016/j.asoc.2012.11.042

[61] Y. Zhong, L. Zhao, L. Zhang, An Adaptive Differential Evolution Endmember Extraction Algorithm for Hyperspectral Remote Sensing Imagery, IEEE Trans. Geosci. Remote Sens. Lett. 11(6) (2014) 1061-1065.

[62] R.W. Kennard, L.A. Stone, American Society for Quality. Technometrics 11 (1969) 137148. https://doi.org/10.2307/1266291

[63] T. Shi, H. Liu, Y. Chen, J. Wang, G. Wu, Estimation of arsenic in agricultural soils using hyperspectral vegetation indices of rice, J. Hazard. Mater. 308 (2016) 243-252. https://doi.org/10.1016/j.jhazmat.2016.01.022

[64] K. Kawamura, Y. Tsujimoto, M. Rabenarivo, H. Asai, A. Andriamananjara, T. Rakotoson, Vis-NIR spectroscopy and PLS regression with waveband selection for estimating the total C and N of paddy soils in Madagascar, Remote Sens. 9 (2017). https://doi.org/10.3390/rs9101081

[65] T. Erudel, S. Fabre, T. Houet, F. Mazier, X. Briottet, Criteria Comparison for Classifying Peatland Vegetation Types Using In Situ Hyperspectral Measurements. Remote Sens. 9 (2017) 748. https://doi.org/10.3390/rs9070748

[66] L. Zhu, Z. Chen, J. Wang, J. Ding, Y. Yu, J. Li, N. Xiao, L. Jiang, Y. Zheng, G.M. Rimmington, Monitoring plant response to phenanthrene using the red edge of canopy hyperspectral reflectance, Mar. Pollut. Bull. 86 (2014) 332-341. https://doi.org/10.1016/j.marpolbul.2014.06.046 
[67] D. Benyó, E. Horváth, E. Németh, T. Leviczky, K. Takács, N. Lehotai, G. Feigl, Z. Kolbert, A. Ördög, R. Gallé, J. Csiszár, L. Szabados, L. Erdei, Á. Gallé, Physiological and molecular responses to heavy metal stresses suggest different detoxification mechanism of Populus deltoides and P. x canadensis, J. Plant Physiol. 201 (2016) 62-70. https://doi.org/10.1016/j.jplph.2016.05.025

[68] E.J. Emengini, G.A. Blackburn, J.C. Theobald, Early detection of oil-induced stress in crops using spectral and thermal responses, J. Appl. Remote Sens. 7 (2013a ) 073596. https://doi.org/10.1117/1.JRS.7.073596

[69] A.K. Knapp, G.A. Carter, Variability in leaf optical properties among 26 species from a broad range of habitats, Am. J. Bot. 85 (1998) 940-946. https://doi.org/10.2307/2446360

[70] I.D. Sanches, C.R. Souza Filho, L.A. Magalhães, G.C.M. Quitério, M.N. Alves, W.J. Oliveira, Unravelling remote sensing signatures of plants contaminated with gasoline and diesel: An approach using the red edge spectral feature, Environ. Pollut. 174 (2013b ) 1627. https://doi.org/10.1016/j.envpol.2012.10.029

[71] J.G.P.W. Clevers, L. Kooistra, M.E. Schaepman, Using spectral information from the NIR water absorption features for the retrieval of canopy water content, Int. J. Appl. Earth Obs. Geoinf. 10 (2008) 388-397. https://doi.org/10.1016/j.jag.2008.03.003

[72] S. Foley, B. Rivard, G.A. Sanchez-Azofeifa, J. Calvo, Foliar spectral properties following leaf clipping and implications for handling techniques, Remote Sens. Environ. 103 (2006) 265-275. https://doi.org/10.1016/j.rse.2005.06.014

[73] T.S. Feild, D.W. Lee, N.M. Holbrook, Why leaves turn red in autumn. The role of anthocyanins in senescing leaves of red-osier dogwood, Plant Physiol. 127 (2001) 566-574. https://doi.org/10.1104/pp.010063

[74] L. Liu, B. Song, S. Zhang, X. Liu, A novel principal component analysis method for the reconstruction of leaf reflectance spectra and retrieval of leaf biochemical contents, Remote Sens. 9 (2017) . https://doi.org/10.3390/rs9111113

[75] Y. Zhang, J. Huang, F. Wang, G.A. Blackburn, H.K. Zhang, X. Wang, C. Wei, K. Zhang, C. Wei, An extended PROSPECT: Advance in the leaf optical properties model separating total chlorophylls into chlorophyll a and b, Sci. Rep. 7 (2017) 1-10. https://doi.org/10.1038/s41598-017-06694-y

[76] C. Nakata, C. Qualizza, M. MacKinnon, S. Renault, Growth and physiological responses of Triticum aestivum and Deschampsia caespitosa exposed to petroleum coke, Water. Air. Soil Pollut. 216 (2011) 59-72. https://doi.org/10.1007/s11270-010-0514-X

[77] Y. Li, N. He, J. Hou, L. Xu, C. Liu, J. Zhang, Q. Wang, X. Zhang, X. Wu, Factors influencing leaf chlorophyll content in natural forests at the biome scale, Front. Ecol. Evol. 6 (2018) 1-10. https://doi.org/10.3389/fevo.2018.00064 
[78] R.E. Martin, G.P. Asner, L. Sack, Genetic variation in leaf pigment, optical and photosynthetic function among diverse phenotypes of Metrosideros polymorpha grown in a common garden, Oecologia 151 (2007) 387-400. https://doi.org/10.1007/s00442-006-0604Z

[79] G.A. Sánchez-Azofeifa, K. Castro, S.J. Wright, J. Gamon, M. Kalacska, B. Rivard, S.A. Schnitzer, J.L. Feng, Differences in leaf traits, leaf internal structure, and spectral reflectance between two communities of lianas and trees: Implications for remote sensing in tropical environments, Remote Sens. Environ. 113 (2009) 2076-2088. https://doi.org/10.1016/j.rse.2009.05.013

[80] V.H. Dorrington, F.B. Pyatt, Some aspects of tissue accumulation and tolerance to available heavy metal ions by Rubus Fruticosus L. A colonizer of spoil tips in S.W. England, Int. J. Environ. Stud. 20 (1983) 229-237. https://doi.org/10.1080/00207238308710039

[81] M.M. Nujkić, M.M. Dimitrijević, S. Alagić, S.B. Tošić, J. V. Petrović, Impact of metallurgical activities on the content of trace elements in the spatial soil and plant parts of Rubus fruticosus L, Environ. Sci. Process. Impacts 18 (2016) 350-360. https://doi.org/10.1039/c5em00646e

[82] G. Kvesitadze, G. Khatisashvili, T. Sadunishvili, J.J. Ramsden, Biochemical mechanisms of detoxification in higher plants, first ed., Springer, Berlin Heidelberg, 2006. https://doi.org/10.1017/CBO9781107415324.004

[83] M. Shahid, C. Dumat, S. Khalid, E. Schreck, T. Xiong, N. Khan Niazi, Foliar heavy metal uptake, toxicity comparison and detoxification in plants: A comparison of foliar and root metal uptake, J. Hazard. Mater. 325 (2017) 36-58. http://dx.doi.org/10.1016/j.jhazmat.2016.11.063

[84] N. Merkl, R. Schultze-Kraft, C. Infante, Phytoremediation in the tropics-the effect of crude oil on the growth of tropical plants, Bioremediat. J. 8 (2004) 177-184. https://doi.org/10.1080/10889860490887 